\title{
Holocene hydro-environmental evolution and its impacts on human occupation in Jianghan- Dongting Basin, middle reaches of the Yangtze River, China
}

\author{
ZHAO Chengshuangping ${ }^{1},{ }^{*} \mathrm{MO}$ Duowen ${ }^{1,2}$ \\ 1. Laboratory for Earth Surface Process, Ministry of Education, College of Urban and Environmental Sciences, \\ Peking University, Beijing 100871, China; \\ 2. Institute of Geographical Sciences, Henan Academy of Sciences, Zhengzhou 450052, China
}

\begin{abstract}
Based on the comprehensive analyses of 18 core profiles' sedimentary sequences and lithological characteristics in Jianghan-Dongting Basin of the middle reaches of the Yangtze River and the spatial-temporal distribution of archeological sites in this area, we reconstructed the Holocene hydro-environmental evolution, and its relationship with human occupation. The comparison reveals: $11.5-5.5 \mathrm{ka} \mathrm{BP}$, the water level of rivers and lakes in the middle Yangtze River appeared a rising trend, concurrently, under the development of Neolithic culture and rice agricultural activities, human occupation extended from piedmont plain to inner basin plain in the study area. The water level fell in 5.5-4.0 ka BP, meanwhile, the number of human settlements of Qujialing-Shijiahe culture rapidly increased, especially in the inner basin plain. The water level rose again around 4.0 ka BP, floods spread massively in this period, which led to the decline of Shijiahe culture. The main causes for hydro-environmental evolution in the study area are the fluctuation of sea level and the aggradation of fluvio-lacustrine sediments.
\end{abstract}

Keywords: Jianghan-Dongting Basin; Holocene; hydrological environmental change; human-environment interaction

\section{Introduction}

Holocene human-environment interactions, which rapidly increased human activities presented a complex relationship with environment, are attractive and perfect case researches of geoarchaeology. Hydro-environmental evolution, which has been proved in many case stud-

Received: $2019-10-27$ Accepted: 2019-12-10

Foundation: The Major Program of the National Social Science Foundation of China, No.11\&ZD183; Foundation for Distinguished Professors of Henan Province; Zhengzhou Research Council for the Origins of Chinese Civilization; National Key Project of Scientific and Technical Supporting Program of China, No.2013BAK08B02; National Natural Science Foundation of China, No.41701220

Author: Zhao Chengshuangping (1991-), PhD Candidate, specialized in environmental evolution and geoarchaeology. E-mail: zhaochengsp@pku.edu.cn

*Corresponding author: Mo Duowen (1955-), Professor, specialized in environmental evolution and geoarchaeology. E-mail:dmo@urban.pku.edu.cn 
ies, also played an important role in human activities and cultural evolution as climate, landform, soil, vegetation and so on. Research in the eastern Sahara desert, west of the Nile, suggested that the area with surface water resource was the key factor which influenced the adaptation strategies of the mobile hunter-gatherers in the desert regions (Bubenzer et al., 2007). By reconstructing the hydro-environmental evolution of Arkansas river and Mississippi river in the lower Mississippi Valley, scholars found that the periods when occurred geomorphic and hydrological change were coincident with periods of major cultural transformation, which suggested climate change, river evolution and flood events play important roles in the interruption and transformation of human occupation and cultural evolution (Kidder et al., 2008). Heyvaert et al. (2008) reconstructed the floodplain history in the surroundings of two ancient Mesopotamian cities: Tell ed-Der and Sippar, basing on the sedimentary analyses of the drill cores in the area, and argued human irrigational activities triggered the realignment of rivers. Research in Indus alluvial plain indicated fluvial quiescence reduced flood stimulating agriculture and encouraging urbanization around 4500 a BP, and further decline in monsoon led rivers to be dry or seasonal which decreased agricultural production supporting Harappan urbanism so that the Harappan civilization collapsed (Giosan et al., 2012). In China, there are also many case studies discussed the interrelation between hydro-environmental change and human activities. Xia et al., (2000) found that terraces and alluvial flat caused by river incising were suitable areas for human occupation, with the river downcutting, human beings gradually migrated to the lower places in the Xar Moron River, Inner Mongolia. Huang et al., (2011) found there was a flood event in 4.3-4.0 ka BP in the Qishui River, middle Yellow River, which was the main cause for the collapse of regional human culture. Studies in the lower Yangtze River suggested that sea level rise was closely related to interruption of human occupation and cultural decline (Zong et al., 2011; Shi et al., 2011; Wu et al., 2014; Chen et al., 2018; He et al., 2018).

The Neolithic cultures in Jianghan-Dongting Basin of the middle Yangtze River originated 9000 years ago, which was a comparatively independent system, played an important role in Chinese prehistoric civilization (Meng, 1997). The environmental evolution, the flourishing and collapse of ancient culture, and their relationship in the middle Yangtze River are heated debate topics that attracted many scholars (Yasuda et al., 2004; Shi et al., 2010; $\mathrm{Wu}, 2013)$. Previous environmental and archaeological studies tried to demonstrate human-environment interaction in the study area. Several studies discussed the relationship between the distribution of settlements and the range of lakes (Du, 2002; Li et al., 2011; Liu et al., 2012; Guo et al., 2014), and some researches argued flood events occurred in Holocene that appreciably impacted human activities (Zhu et al., 1997; Wang, 1998; Xie et al., 2007; Wu et al., 2015). Previous studies always respectively discussed the Jianghan Plain and the Dongting Basin, rarely analyzing this area as a whole geomorphologic region. And the process of hydro-environmental evolution and its forcing mechanisms were not only clear, but also its effects on human cultural evolution.

Based on the comprehensive analyses of 18 core profiles' sedimentary sequences and lithological characteristics in Jianghan-Dongting Basin of the middle Yangtze River and the spatial-temporal distribution of archeological sites in this area, we reconstructed the Holocene hydro-environmental evolution of the study area, and discussed its relationship with human activities. 


\section{Study area}

The Jianghan-Dongting Basin, lying in the middle Yangtze River, is composed of Jianghan Plain north of the river and Dongting Basin south of the river. The Jianghan Plain is located in the south-central Hubei Province and the Dongting Basin in the northern Hunan Province, which are divided by Huarong Uplift. The Jianghan-Dongting Basin is surrounded by mountains with alluvial-lacustrine plain in the center. There are developed drainage systems in the study area, where the Yangtze and its tributaries are the major rivers. The Dongting Lake is the largest lake in the area (Figure 1), which has a subtropical monsoon climate, characterized by alternating winter and summer monsoons as well as four distinctive seasons. The mean annual temperature is $16-18^{\circ} \mathrm{C}$ and the mean annual precipitation reaches 1000-1400 mm, mainly concentrating from April to September and accounting for over $70 \%$ of the annual total (Wang et al., 2009). Subtropical evergreen broad-leaved forest is the main vegetation type.

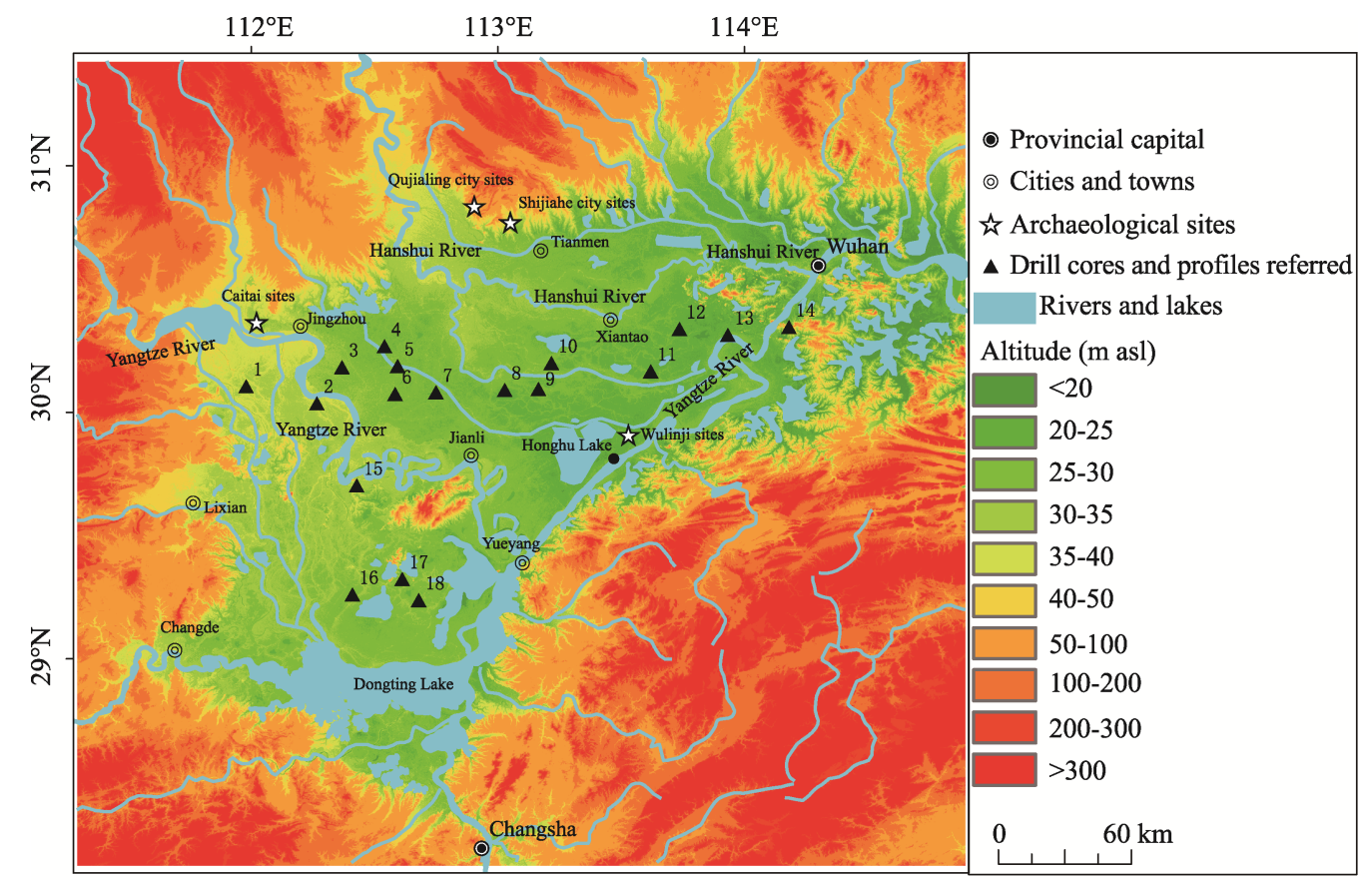

Figure 1 Location of Jianghan-Dongting Basin, middle reaches of the Yangtze River, China and drill cores

1. Songzibabao188. 2. MHK02. 3. JZ-2010. 4. Zhangjinhai345. 5. 47. 6. QS01. 7. Xingou. 8. Zhoulao. 9. WS03. 10. M1. 11. DTH01. 12. Chunliangling454. 13. ZK76. 14. ZK84. 15. Wanzikou274. 16. CK37. 17. CK21. 18. ZK01.

\subsection{Geomorphological setting}

The Jianghan-Dongting Basin is surrounded by mountains, such as Jingshan, Dahongshan, Tongbaishan and Dabieshan on the north, Mubushan on the east, Xuefengshan on the south and Wulingshan on the east. Hills are distributed between mountains and plains. The inner part of the plain mainly consists of high alluvial plain, alluvial-lacustrine plain, and low 
mountains and hills with loess scattering around. The landform of the high alluvial plain (30-40 m asl) located at the edge of the basin, front of the mountains, especially on both banks of the Yangtze River in the west basin is flat and its main deposited sediments are Quaternary fluvial deposition. The alluvial-lacustrine plain $(30 \mathrm{~m}$ asl) is the central part of the basin with the flattest landform and the Quaternary lacustrine deposits. The hills ( $>200 \mathrm{~m}$ asl) in the basin spread on Taohuashan, Huangshantou and so on. The Loess Plateau which is constituted by the mid-late Pleistocene laterite and loess is distributed in the inner plain of the basin with elevations of 1-2 m higher than the surroundings.

There are dense rivers and lakes in the Jianghan-Dongting Basin. The Yangtze River flows into the basin from the northwest, and turns to the northeast at Yueyang, then eastward outflow the basin at Wuhan, which created many oxbow lakes in the border area of Hubei and Hunan provinces. In the north basin, the Hanshui River, the largest tributary of the Yangtze River, enters the Jianghan Plain from the north and flows toward southeast, and turns to east at Tianmen, into the Yangtze River at Hankou. In the south basin, there is the Dongting Lake hydrographic net, including Xiangshui River, Zishui River, Ruanshui River and Lishui River. These rivers together with the Yangtze River, Hanshui River, and other tributaries constitute the river network of the Jianghan-Dongting Basin. Depressions between rivers always developed into interfluvial lakes (Figure 2).

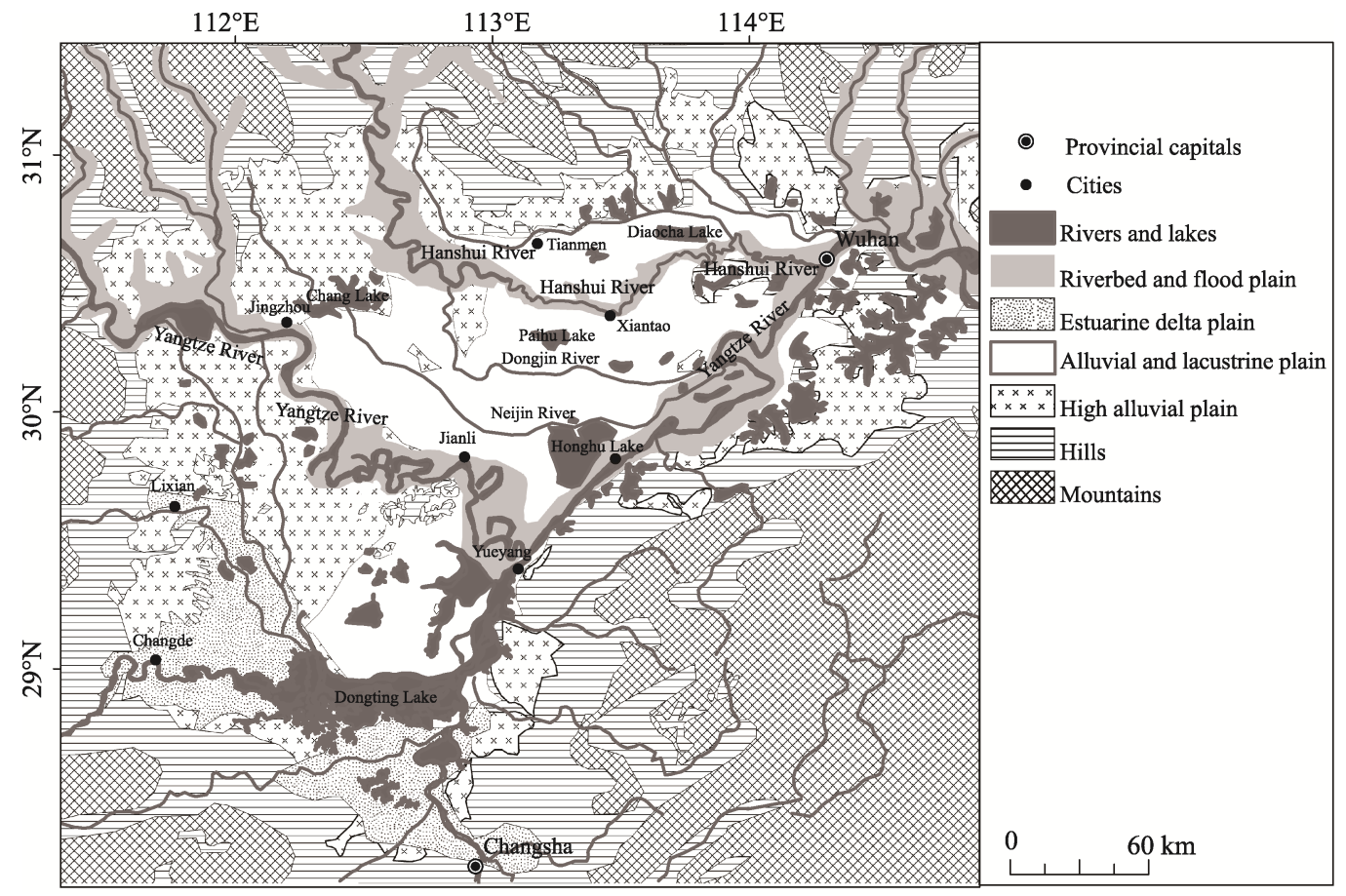

Figure 2 Geomorphologic map of Jianghan-Dongting Basin, middle reaches of the Yangtze River, China

\subsection{Archaeological backgrounds}

As the archaeological works rapidly propelled, the Neolithic sequence of the Jianghan-Dongting Basin is more and more clear (Meng, 1997; Guo, 2010), which could be divided into three stages. 


\subsubsection{The early-Neolithic}

The earliest Neolithic culture in the middle reaches of the Yangtze River is Pengtoushan culture (8.5-7.8 ka BP), which centered in the Liyang Plain of the Dongtong Lake area. Gathering and hunting were the principal subsistence means of the Pengtoushan culture, and early rice agricultural activities had begun, while moated settlements formed. The following Zaoshixiaceng culture (7.8-6.9 ka BP) and Tangjiagang culture (6.9-6.3 ka BP) still occupied the Dongting Basin. Meanwhile, the Chengbeixi culture (7.8-6.3 ka BP), which originated from Pengtoushan culture, was found on both banks of the Yangtze River in western Hubei Province. In the Jianghan Plain, Bianfan culture (6.9-5.9 ka BP), which was characterized by a mixed local and Yellow River culture, developed along the Hanshui River.

\subsubsection{The middle-Neolithic}

The Daxi culture (6.3-5.5 ka BP), a follow-up of the Chengbeixi culture, spread over the Jianghan-Dongting Basin and the Three Gorges Area. In this period, the Chinese earliest prehistoric city, Chengtoushan site was constructed in the Dongting Basin. Rice farming was further developed, paddy fields as well as irrigation system, were discovered (He, 1999). Meanwhile, Youziling culture (5.9-5.3 ka BP) originated from Bianfan developed in the Jianghan Plain.

\subsubsection{The late-Neolithic}

Qujialing culture (5.3-4.5 ka BP) occupied and spread all over the middle Yangtze region. Culture prosperity and many prehistoric settlements and city sites occurred in this period (Wang, 2003). Rice farming grew into a much larger scale to feed the increasing 'rural and urban population'. In the Shijiahe culture (4.5-3.9 ka BP), the settlements were hierarchical, and the number of the settlements reached to a maximum level of Neolithic. The Shijiahe ancient city site became the capital of the middle Yangtze, which implied the prehistoric culture in the middle Yangtze River had been developed into the early stage of civilization (Guo, 2010). However, the prosperous culture collapsed around 4.0 ka BP, when the large numbers of settlements were abandoned, the number of sites sharply decreased. This decrease lasted until the Shang Dynasty, then, the human activities revived again in the middle Yangtze River.

\section{Hydro-environmental evolution}

According to the evolutional history of environment and cultures (Table 1 and Figure 3), the hydro-environmental evolution of the Jianghan-Dongting Basin could also be divided into three periods, i.e., 11.5-5.5 ka BP, 5.5-4.0 ka BP and after 4.0 ka BP.

In the Last Glacial Maximum (LGM), while rainfall reduced, the base level of erosion decreased due to sea level decline. The rivers in the middle Yangtze River were severely cutting down and the lakes dried up under the impact of headward erosion, which led to the landscape of plain with deeply incised valleys. The water level of the study area was in the lowest position. As the accumulation of sand gravel formed in glacial period, the riverbeds were aggrading. Until the last stage of late Pleistocene, the lakes spread from the incised valleys and low-lying area (Xu and Xie, 1994; Deng, 2004). 
Table 1 The list of sediment cores

\begin{tabular}{|c|c|c|c|}
\hline Number & Name & Location & References \\
\hline 1 & Songzibabao188 & Babao town, Songzi city, Jingzhou city, Hubei province & Jin Boxin, 1992 \\
\hline 2 & MHK02 & Mahaokou town, Gongan county, Hubei province & Chen and Wang, 2014 \\
\hline 3 & JZ-2010 & Jiangbei farm, Jiangling district, Jingzhou city, Hubei province & Li F et al., 2014 \\
\hline 4 & Zhangjinhai345 & Zhangjin town, Qianjiang city, Hubei province & Jin Boxin, 1992 \\
\hline 5 & 47 & $\begin{array}{l}\text { Liuheyuan farm, Jiangling district, Jingzhou city, Hubei prov- } \\
\text { ince }\end{array}$ & Shi Zhixin, 1997 \\
\hline 6 & QS01 & Qinshi town, Jiangling district, Jingzhou city, Hubei province & Chen and Wang, 2014 \\
\hline 7 & Xingou & Xingou town, Jianli county, Hubei province & Wang and Li, 2009 \\
\hline 8 & Zhoulao & Zhoulao town, Jianli county, Hubei province & $\begin{array}{l}\text { Zhang Yufen et al., } \\
2005\end{array}$ \\
\hline 9 & WS03 & Yijiawan, Wangshi town, Jianli county, Hubei province & Chen and Wang, 2014 \\
\hline 10 & M1 & Miancheng town, Xiantao city, Hubei province & Zhu Yuxin et al., 1997 \\
\hline 11 & DTH01 & Datonghu farm, Honghu city, Hubei province & Chen and Wang, 2014 \\
\hline 12 & $\begin{array}{l}\text { Chunliang- } \\
\text { ling454 }\end{array}$ & Chunliangling, Xiantao city, Hubei province & Jin Boxin, 1992 \\
\hline 13 & ZK76 & Caidian district, Wuhan city, Hubei province & Chen and Wang, 2014 \\
\hline 14 & ZK84 & Mentangwan, Jiangxia district, Wuhan city, Hubei province & Chen and Wang, 2014 \\
\hline 15 & Wanzikou 274 & Wanzikou, Shishou city, Jingzhou city, Hubei province & Jin Boxin, 1992 \\
\hline 16 & CK37 & The western Dongting lake region, Hunan province & $\begin{array}{l}\text { Zhang Xiaoyang et al., } \\
1994\end{array}$ \\
\hline 17 & CK21 & Zhuzikou town, Huarong county, Hunan province & $\begin{array}{l}\text { Zhang Xiaoyang et al., } \\
1994\end{array}$ \\
\hline 18 & ZK01 & Zhuzikou town, Huarong county, Hunan province & Li Jun, 2009 \\
\hline
\end{tabular}

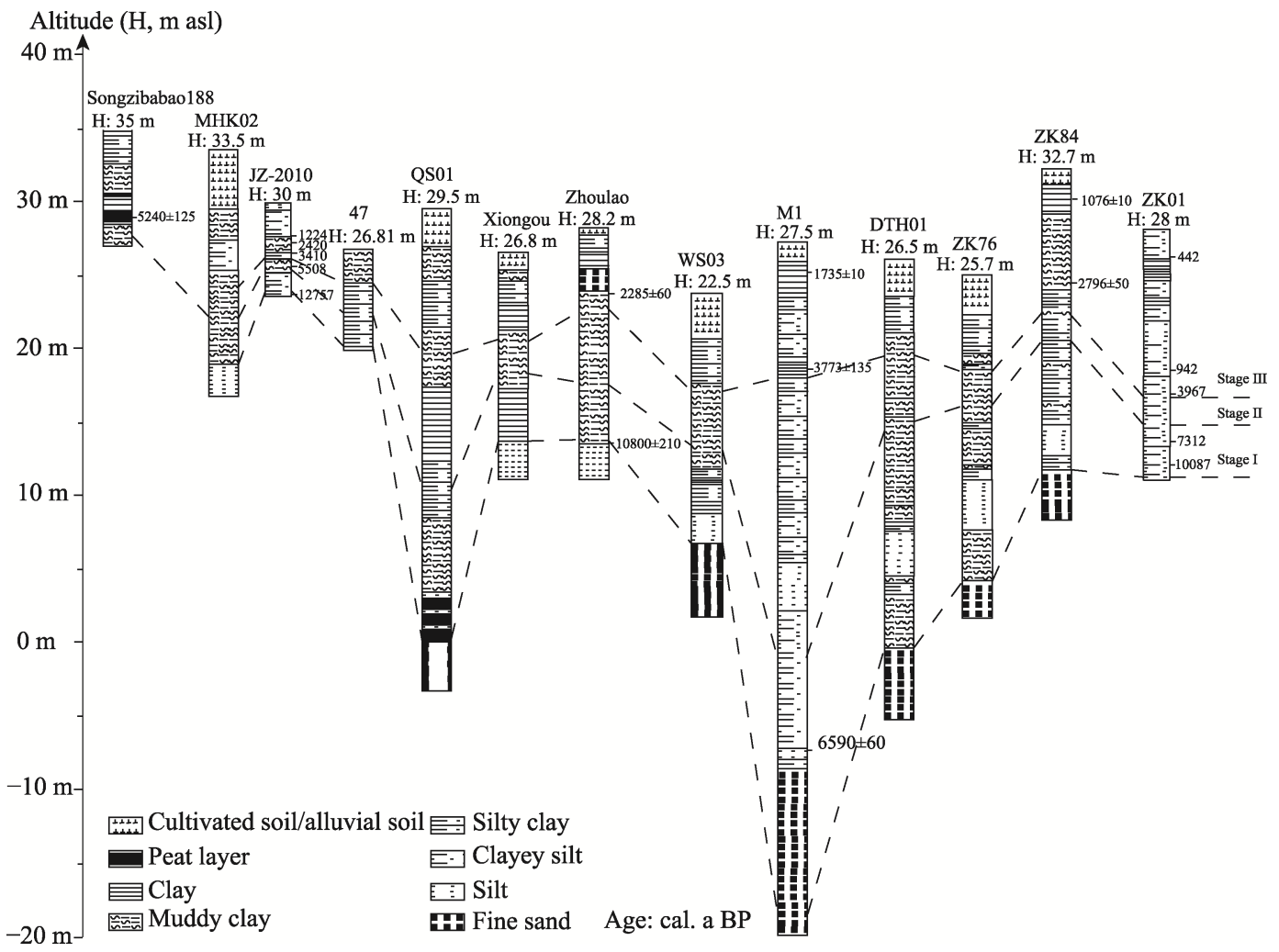

Figure 3 Diagram illustrating the main Holocene sediment cores and profiles 


\subsection{Period I (>11.5-5.5 ka BP)}

The JZ-2010 profile $\left(112^{\circ} 22^{\prime} 02^{\prime \prime} \mathrm{E}, 30^{\circ} 11^{\prime} 01^{\prime \prime} \mathrm{N}\right)(\mathrm{Li}$ et al., 2014) is located in Jingzhou of Hubei Province, the western Jianghan Plain. The geomorphic location is on the back of natural levee of the Yangtze River. An interfluvial low-lying lake existed. In the late Pleistocene to the mid-Holocene (637-470 $\mathrm{cm}$ deep from top of the profile), the deposition of the site was clayey silt with greyish yellow-brown color. From the bottom to the top of this stratum, the grain size was gradually diminishing with the increasing content of clay and the decreasing of silt (Figures 3 and 4), which indicated a stable lacustrine sedimentary environment with a rising water level. From a depth of $470 \mathrm{~cm}$ (about $7.0 \mathrm{ka} \mathrm{BP}$ ), the color of the sediments turned to deep greyish green with the sharply increasing content of clay but the decreasing of silt, which implied a comparatively deeper water. The 47 drill core (Shi, 1997) is close to the JZ-2010. The sediment was greyish brown clay from late Pleistocene to late Holocene. The tendency of diatom's quantity and species was decreasing sharply, but the planktonic species was increased, implying the flood of the Yangtze River affected the decline of the quantity and species of diatom. Moreover, the other species except the planktonic ones did not adapt to the rise of water level. The Xingou core (Wang and Li, 2009), Zhaolao core (Zhang et al., 2005) and Yijiawan WS03 core (Chen and Wang, 2014) in central Jianghan Plain and the M1 core (Zhu et al., 1997) in Xiantao city (Figure 3) have recorded the transfer from fluvial facies to lacustrine facies in the late Pleistocene to the mid-Holocene in the Dongjing River region, which indicated the development of interfluvial low-lying lake.

The ZK01 core ( $\mathrm{Li}, 2009)$ is located in the ancient deep groove of the west bank of east Dongting Lake, the eastern Dongting Basin. The sediment of the core was stable steel grey silty clay (Figure 3) with horizontal stratification, implied a deep and stable lake in this place from the last stage of the late Pleistocene. Before $7312 \mathrm{cal}$. a BP, the grain size of the core slightly changed, indicating the dynamic balance with rising water level and the lacustrine process. After $7312 \mathrm{cal}$. a BP, the grading curve obviously fluctuated that the coarse silt became more and the clay and fine silt diminished (Figure 4), which indicated the water level of the lake was reduced. The processes were impacted by the fact that the rising rate of deposition was faster than the rising rate of water level, which was the natural process of the lake development, implied the quick rising trend of water level of the Yangtze River from $7.0 \mathrm{ka}$ BP was slowing down. The early-Holocene sediments almost disappeared in the whole Dongting Basin, but only deposited on the ancient deep notch or some lowlands (Cai and Guan, 1982; Yang, 1986; Liu et al., 2012). The sediments of the first stage of mid-Holocene rarely developed in some lowlands too (Lai et al., 2004). The chronology of the widely distributed lacustrine deposition appeared at later age, such as the ${ }^{14} \mathrm{C}$ age of the shell in the bottom of the bluish green clay belt in Ruanjiankou to east Dongting Lake was $7588 \pm 150$ cal. a BP, indicating the age of the lake formation. This deposit sediment reflected that the ancient Dongting Lake formed from the ancient deep groove in the late Pleistocene, and the main part of the Lake lied on the north of the Dongting Lake region and the tail end area of the ancient Xiangjiang River gradually spread around as the water level rising.

From late Pleistocene to mid-Holocene, the water level of the middle Yangtze River rose rapidly. About $7.0 \mathrm{ka} \mathrm{BP}$, the rate of rise was slower than before. The long-term high water level led to a rapid deposition in the deep groove by river erosion, development of lake in 
the lowlands and the deep grooves. This process was probably related to the climate and sea level changes after the last glacial period. On one hand, warmer climate and increased precipitation intensified the erosion and transportation capacity of rivers, which could carry more and more fragmentary material by physical weathering in cold climate to the river valleys, increasing the quantity of water and sand. On the other hand, the rise of sea level in East China (Yang and Xie, 1984; Horton et al., 2006; Bird et al., 2010) raised the base erosion level and water level of the Yangtze River. Under the backwater effect of the Yangtze River, headward accumulation caused the accumulation of sediment from the river net of Jianghan-Dongting Basin so that the water level rose. At the beginning, the water level of Yangtze River was lower than the ground (Zhou, 1990; Xu and Xie, 1994), and the fragmentary materials carried by river deposited in the deep grooves and lowlands that supported the lake extension from this area first. With the rise of sea level and aggradation of grooves and lowlands, the water level of the Yangtze River was increasing. Sometimes the flood could overflow the river banks and deposited thin layer sediments, like the early-Holocene flood sediments in Sihu Depression and Chonghu Lake in Jianghan Plain (Cai et al., 1998). Around $7.0 \mathrm{ka} \mathrm{BP}$, the deceleration of sea level rise (Zheng et al., 2018) led to the deceleration of water level rise in the Jianghan-Dongting Basin, which caused lakes became shallower and some lowlands in plains turned to be lakes.

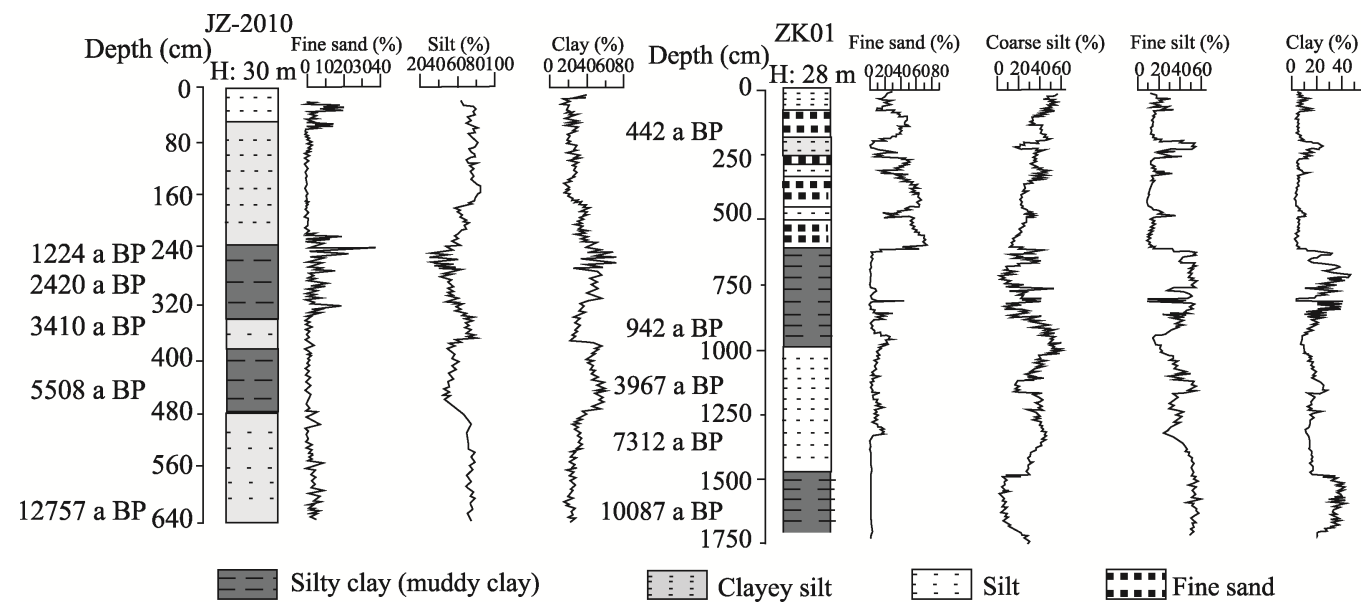

Figure 4 Grading curve of JZ-2010 (Li F et al., 2014) and ZK01 (Li Jun, 2009)

\subsection{Period II (5.5-4.0 ka BP)}

At the last stage of mid-Holocene, the sediment characteristics obviously changed. At the JZ-2010 (Wu, 2013; Li et al., 2014), there was a layer of dark brown sludge suggesting a deep interfluvial lake environment dating to the mid- to late-Holocene (Figure 3). In this layer, at $437 \mathrm{~cm}(5508 \mathrm{cal}$. a BP), the content of clay decreased but the silt increased (Figure 4) indicating the depth of lakes reduced which implied a stage of lower water level of Jianghan Plain. The Songzibabao 188 core (Figure 3), the Zhangjinhai 345 core in the western Jianghan Plain, the Chunliangling 454 core in the east-central Jianghan Plain, and the Wanzikou 274 core in the southern Jianghan Plain (Jin, 1992; Deng, 2004) are located in lakes and marshes area near rivers, and the sediments in these cores showed that between the late 
and mid-Holocene lacustrine layers were thin layers of fine sand, mild sand or clay. The AMS ${ }^{14} \mathrm{C}$ dating of this layer in the Songzibabao 188 core (Jin, 1992; Deng, 2004) suggested the water level had significantly decreased before $5240 \pm 125$ cal. a BP. Other cores in this period showed the sedimentary facies changed frequently, such as alternating layers of muddy clay, silty clay and clay in the QS01 in Jiangling, the DTH01 in the Datong Lake, the ZK76 and ZK84 in Wuhan (Chen and Wang, 2014) (Figure 3) indicating the unsteadiness of lakes caused by decline of water level. The grain size of ZK01 in Dongting Lake obviously varied at $130 \mathrm{~cm}(5.5 \mathrm{ka} \mathrm{BP})$ that the sand and coarse silt increased, and the fine silt decreased (Figure 4), which implied a period of water level decline.

The sea level of East China fell about 5.5 ka BP (Yang and Xie, 1984), and then the base level of erosion fell. The headward erosion led to the Yangtze River cutting down, then the water level of lakes along the Yangtze River declined. A direct evidence was the hiatus in 5.5-5.0 ka BP in the Taihu Lake (Yasuda et al., 2004). The decline of water level also influenced the middle Yangtze River. Furthermore, the abrupt climate change event in $5.5 \mathrm{ka} \mathrm{BP}$ reduced the precipitation that enhanced the decline of water level of rivers and lakes, so that there was a low water level period in the middle Yangtze River.

\subsection{Period III (after 4.0 ka BP)}

The significant changes of sedimentary characteristics happened in late-Holocene. The Miancheng M1 core $\left(113^{\circ} 13^{\prime} \mathrm{E}, 30^{\circ} 12^{\prime} \mathrm{N}\right)$ (Zhu et al., 1997) was in Paihu Lake depression between Hanshui River and east Jingjiang River, and was in Mianyang sag geologically, the central Jianghan Plain, where turned river into lake about $6.5 \mathrm{ka}$ BP. At $14 \mathrm{~m} \mathrm{(4.2} \mathrm{ka} \mathrm{BP)} \mathrm{in}$ the core, the grey brown silty clay interbedded with grey silt became grey to dark grey clay (Figures 3 and 4). The darker color and smaller size of the sediments indicated the water level was rising and the lake was more stable. From the west to the east, cores in the Jianghan Plain deposited on muddy clay, such as MHK02 in Gongan (Chen and Wang, 2014), ZK47 (Shi, 1997) in Jiangling, QS01 (Chen and Wang, 2014) in Qinshi, Xingou core (Wang and Li, 2009) and Zhoulao core (Zhang et al., 2005) in Jianli, WS03 (Chen and Wang, 2014) in Wangshi, ZK76 (Chen and Wang, 2014) in Wuhan and so on (Figure 3). The grain size in these cores was smaller than before, suggesting the increasing of both lakes' area and quantity. However, the analysis of JZ-2010 showed a decrease of clay, increase of silt, and the grain size became larger (Figure 4). According to its special geomorphological features, JZ-2010 was located on the back of natural levees of the Yangtze River. When water level of the Yangtze River rose, flood would break through the natural levees and carry numerous sediments into JZ-2010 to make crevasse fan deposits, of which the grain size was larger.

The ZK01 in Dongting Lake showed the decreasing coarse silt and the increasing fine silt and clay, indicating the lake level was rising (Li, 2009) (Figure 4). Because of the connection between Dongting Lake and Yangtze River, the water level of Dongting Lake could reflect the water level of the Yangtze River. In the whole Dongting Basin, the sediments were mainly the clayey silt and silty clay, and some muddy silt and silty mud interspersed. The ${ }^{14} \mathrm{C}$ dates from the bottom of muddy fine silt layer of CK37 in west Dongting Lake was $3900 \pm 100$ cal. a BP, and the ${ }^{14} \mathrm{C}$ dates from the inner lacustrine layer of CK2 1 in east Dongting Lake was $3700 \pm 100$ cal. a BP (Zhang et al., 1994), which confirmed the expansion of the Dongting Lake occurred about 4.0 ka BP. 
Apart from climate changes (Yasuda et al., 2004; Li et al., 2013), the re-rise of the sea level in this period (Cai and Guan, 1982; Yang and Xie, 1984; Wang, 1999; Lai et al., 2004; Zheng et al., 2012; Xie and Yuan, 2012) played an important role in water level of the middle Yangtze River. Aggrading from late Pleistocene flattened the Jianghan-Dongting Basin around $4.0 \mathrm{ka} \mathrm{BP}$, so that the early river cutting plain turned to fluvio-lacustrine plain which would overflow more often. Under the backwater effect of seawater, the water level of rivers and lakes increased which led to large-scale flooding as well as lakes forming in lowlands.

\section{Human-environment interaction}

The water level of rivers and lakes in the middle Yangtze River rose in 11.5-5.5 ka BP, and fell in 5.5-4.0 ka BP, and then rose again around 4.0 ka BP. The three periods of water level fluctuation influenced the human occupation, agricultural activities and the development of Neolithic culture.
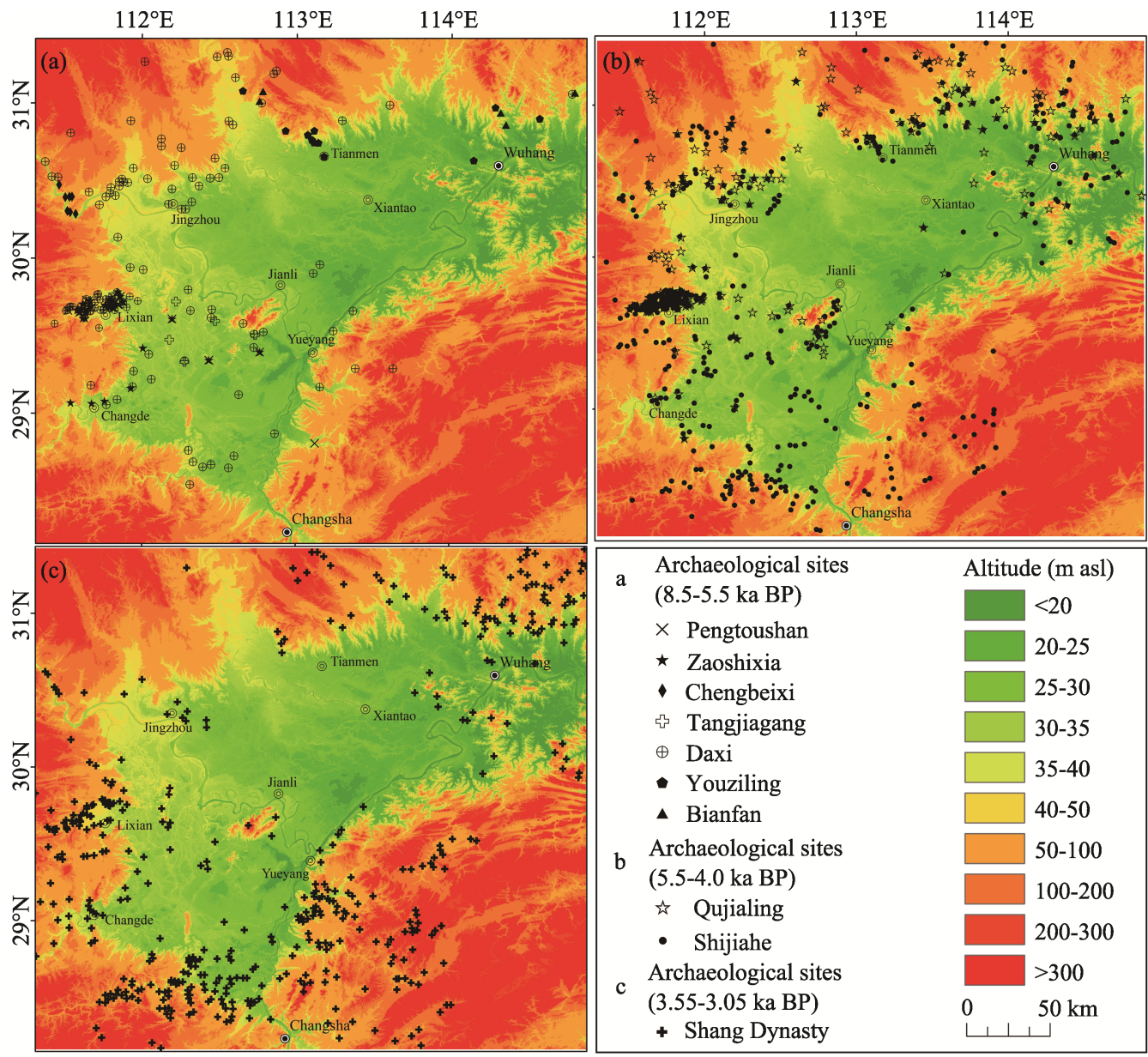

Figure 5 Settlement distribution during Holocene (adapted from Deng Hui, 2009)

\section{$4.1 \quad 8.5-5.5 \mathrm{ka} \mathrm{BP}$}

In the early-mid Holocene the cultural sequence in the Dongting Lake and the western Ji- 
anghan Plain were Pengtoushan, Zaoshixiaceng, Chengbeixi, Tangjiagang and Daxi. Meanwhile in the northern Jianghan Plain there were Bianfan and Youziling cultures. In 8.5-6.3 ka BP (Pengtoushan, Zaoshixiaceng, Chengbeixi, Tangjiagang, and Bianfan cultures), there were a few settlements (Figures 5a and 6) in the piedmont plains (Zhu et al., 2007; Deng et al., 2009; Liu et al., 2012; Da, 2013; Guo et al., 2014). From the perspective of cultural continuity, from the Paleolithic Age to the Paleolithic-Neolithic transitions, the piedmont plains of Liyang Plain in Dongting Basin were important habitations for humans (Pei, 2000), so the earliest Neolithic culture was originated in this region. From the perspective of economic subsistence, the piedmont plains were convenient for gathering and hunting, and supported rice farming as well (HICRA, 2006). Furthermore, the piedmont plains were able to accommodate a small population to subsist, and human beings did not have to migrate into Liyang Plain. In 6.3-5.3 ka BP (Daxi and Youziling cultures) (Figure 5a), the number of settlements increased (Figure 6), and including the piedmont plains human also occupied the inner plain (Zhu et al., 2007; Deng et al., 2009; Liu et al., 2012; Da, 2013; Guo et al., 2014). There were two reasons for the transformation. One was the piedmont could not support the increasing population and settlements which drove human beings to migrate into the wider plain region. The other was that the full-fledged rice farming (HICRA, 2007) became the main subsistence instead of gathering and hunting, so that human preferred to live on the plain that was more suitable for rice farming. The change of this period was predominantly associated with the human cultural development, which means even though the water level was rising but it did not have impact on distribution of human occupation.

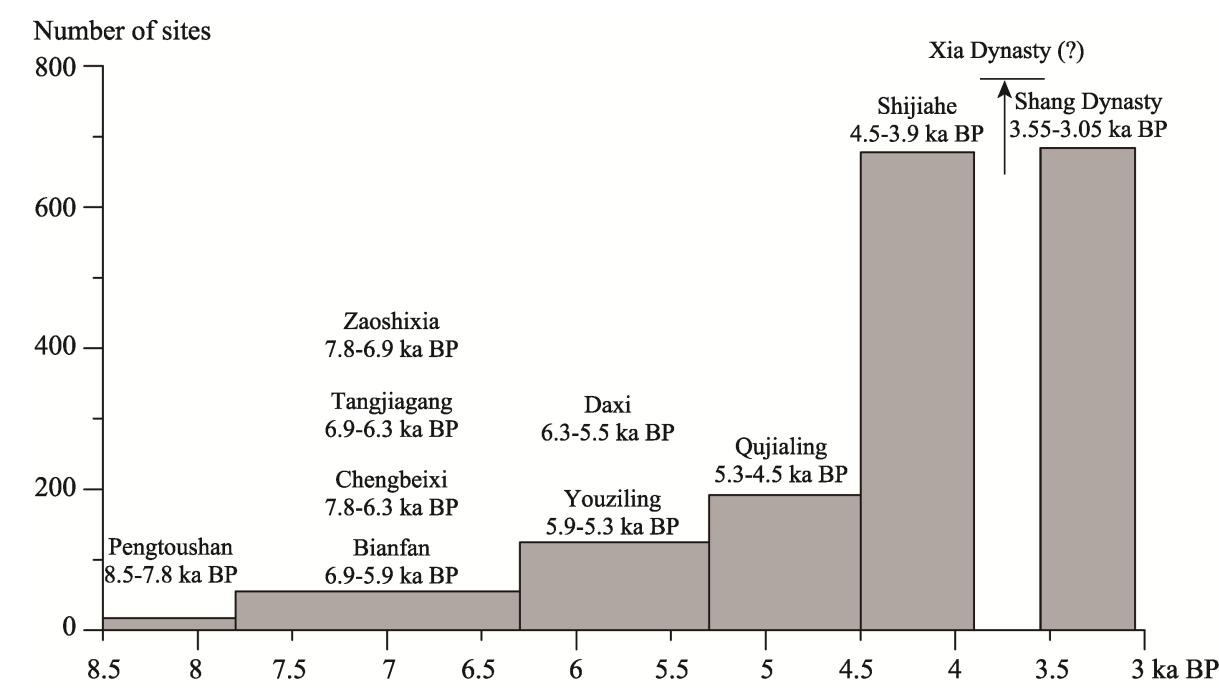

Figure 6 Histogram showing the number of sites in the middle reaches of the Yangtze River

\section{$4.2 \quad 5.5-4.0 \mathrm{ka} \mathrm{BP}$}

In the last stage of mid-Holocene, the Neolithic cultures in the Jianghan-Dongting Basin were the Qujialing culture (5.3-4.5 ka BP) and the early-mid Shijiahe culture (4.5-4.2 ka BP). The number of settlements increased and spread into the fluvio-lacustrine plain, and the number of settlements in the Jianghan Plain was larger than that of Dongting Basin in the Qujialing period (Figure 5b). Qujialing culture which originated from Youziling culture, 
unified the middle reaches of the Yangtze River, and created a flourish culture in Chinese prehistory (Wang, 2007). The prehistoric walled and moated sites were constructed in this period, such as the Shijiahe site, the Taojiahu site, the Yinxiangcheng site and Jimingcheng site, etc., and as central sites they were surrounded by many contemporary satellite settlements (Wang, 2003). In the early-mid Shijiahe period, the number of settlements further increased than that of Qujialing (Figure 6), and the distribution range enlarged to Funiu Moutain and southern Huaihe River in the north, Dongting Lake in the south, Xiling Gorge in the west and Bahe River in the east (Zhu et al., 2007). The settlements were also distributed along the various geomorphological areas at altitudes of 27-200 m (Figure 5b). The Shijiahe site with dominant position was the capital site in the middle Yangtze River. The society of Shijiahe was more complex and the political organization was mature. Some large-scale sites for worship were excavated (Meng et al., 2017). That means the human culture in the middle Yangtze River could be regarded as primary civilization (Guo, 2010; Meng et al., 2017).

The process of cultural development was bound up with the hydro-environmental evolution. Around $5.5 \mathrm{ka}$ BP, the drop of water level of the middle Yangtze River reduced the range of lakes so that the range of lands for human occupation expanded, which was beneficial to the increase of the number of settlements. For another, the large fertile fields in plains were suitable for rice cultivation, promoting rice farming to be gradually overwhelmingly important in economic subsistence, which supported densely populated regions' cultural development. Researches in the lower Yangtze River had revealed sea level at a low position 5.0-4.5 ka BP when the Liangzhu culture (5.3-4.3 ka BP) developed (Shi et al., 2011; He et al., 2018). It implied that there was a low water level in the middle to lower Yangtze River caused by decreasing sea level, which contributed to human occupation and domestication of rice. As a result the human culture was prosperous in this period.

\subsection{After 4.0 ka BP}

About $4.0 \mathrm{ka} \mathrm{BP}$, the late Shijiahe culture, the large-scale ancient sites were abandoned, and the settlement form with Shijiahe site as the center was broken down. Settlements decreased and scattered (Wang, 1998; Guo et al., 2014), and the cultural features changed under the influence of Central Plain Culture (SAT, 1992). The prosperous Neolithic culture in the middle Yangtze River was collapsed and then followed a low tide of cultural development which continued hundreds of years. Until the Shang Dynasty (3.55-3.05 ka BP) the human beings were active in the Jianghan-Dongting Basin again (Figure 6), but most of the sites were located on the higher hills and mountains in the marginal region of the basin, and only a little lay in the inner plain (Figure 5).

The rising of water level at about $4.0 \mathrm{ka} \mathrm{BP}$ may be one of the main causes for the collapse of the Shijiahe culture. The aggradation in the incised valleys from late Pleistocene led the central Jianghan-Dongting Plain to a flat flood-prone fluvio-lacustrine plain around 4.0 ka BP, and intensified by the rising water level of the middle Yangtze River due to sea level rise (Cai and Guan, 1982; Yang and Xie, 1984; Wang, 1999; Lai et al., 2004; Zheng et al., 2012; Xie and Yuan, 2012). The long-term and frequent overflow had negative influence on human activities. Some sites in the lower sections were abandoned directly by flooding, such as Caitai site in Jiangling and Wulinji site in Honghu Lake, both with a 1-m muddy layer on the Shijiahe culture layer (Wang, 1998). Most of the sites in the higher sections with walls 
and moats were away from the overflow, but the paddies of them were always in the lower plain of the peripheries of the sites that were easy to be submerged by overflow caused the shortage of food, which could not support the maintenance of large-scale sites such as Shijiahe. Then social contradictions burst out and the population declined. Eventually the Shijiahe culture collapsed. The previous researches in the lower Yangtze River revealed sea level rise around 4.0 ka BP (Zhao et al., 1979; Wang, 1999; Zheng et al., 2012) which may have been the main cause for the collapse of Liangzhu culture (Stanley and Chen, 1996; Zhang et al., 2004; Shi et al., 2011).

\section{Conclusion}

Analysis of the 18 core profiles' sedimentary sequences and lithological characteristics in the Jianghan-Dongting Basin of the middle reaches of the Yangtze River and the spatial-temporal distribution of the archeological sites in this area shows the Holocene hydro-environmental evolution and its relationship with human activities.

From the last stage of late Pleistocene the water level was rising quickly, then the rate of rising became slower at about $7.0 \mathrm{ka} \mathrm{BP}$. Around $5.5 \mathrm{ka} \mathrm{BP}$ the water level slightly decreased, and around $4.0 \mathrm{ka} \mathrm{BP}$, water level increased again.

Human activities were closely associated with the evolution of hydro-environment. In 8.5-5.5 ka BP, the stage of water level rise, the number of settlements was small, and the distribution and migration of settlements were controlled by cultural continuity, populated density, and rice agriculture, instead of water level. In 5.5-4.0 ka BP, with the water level in a comparatively low position, the settlements increased and spread obviously, and the Shijiahe site as the capital site was established, which means the human culture in the middle Yangtze River was developed into early stage of civilization. About $4.0 \mathrm{ka} \mathrm{BP}$, the re-rise of the water level led to the collapse of Shijiahe culture, and the number of sites decreased.

The forcing mechanisms of water environmental evolution were the driver of the sea level change and the aggradation of fluvio-lacustrine sediments. The increasing sea level resulted in water level rising, and the decreasing sea level resulted in water level falling. The aggradation of fluvio-lacustrine sediments made the study area prone to flood which intensified the influence of water level rise.

\section{References}

Bird M I, Austin W E N, Wurster C M et al., 2010. Punctuated eustatic sea-level rise in the early mid-Holocene. Geology, 38(9): 803-806.

Bubenzer O, Riemer H, 2007. Holocene climatic change and human settlement between the central Sahara and the Nile Valley: Archaeological and geomorphological results. Geoarchaeology, 22(6): 607-620.

Cai S, Guan Z, 1982. The ungrounded hypothesis of the presence of the ancient Yunmeng swamp traversing south and north of Yangtze River on the Jianghan-Dongting Plain: Second comments on the ancient Yunmeng swamp. Oceanologia et Limnologia Sinica, 13(2): 129-142. (in Chinese)

Chai S, Zhao Y, Du Y et al., 1998. Environmental evolution and future development trend of Jianghan Lake Group in Holocene: Reunderstanding of ancient Yunmengze problem. Journal of Wuhan University (Humanities Section), (6): 96-100. (in Chinese)

Chen S, Wang X, 2014. Discussion on topography and environmental changes of Jianghan Plain since the Holocene. Geographical Science Research, (3): 39-45. (in Chinese) 
Chen T, Ryves D B, Wang Z et al., 2018. Mid to late Holocene geomorphological and hydrological changes in the south Taihu area of the Yangtze Delta Plain, China. Palaeogeography, Palaeoclimatology, Palaeoecology, 498: $127-142$.

Da H, 2013. Relationship between Neolithic settlement distribution and environment in the middle reaches of Yangtze River (1). Huaxia Archaeology, (3): 36-43. (in Chinese)

Deng H, 2004. Study on the evolution and sustainable development of Jianghan Lake Group [D]. Shanghai: East China Normal University. (in Chinese)

Deng H, Cheng Y, Jia J et al., 2009. Distribution patterns of the ancient cultural sites in the middle reaches of the Yangtze River since 8500 a BP. Acta Geographica Sinica, 64(9): 1113-1125. (in Chinese)

Du Y, 2002. Neolithic ashes and historical environment in the Dongting Lake area. Journal of Central China Normal University (Nat. Sci.), 36(4): 516-520. (in Chinese)

Giosan L, Clift P D, Mcklin M G et al., 2012. Fluvial landscapes of the Harappan civilization. Proceedings of the National Academy of Sciences, 109(26): 1688-1694.

Guo W, 2010. The Culture and Society of Liyang Plain and Handong Area in the Neolithic Age. Beijing: Cultural Relics Press. (in Chinese)

Guo Y, Mo D, Mao L et al., 2014. Settlement distribution and its relationship with environmental changes from the Paleolithic to Shang-Zhou period in Liyang Plain, China. Quaternary International, 321: 29-36.

He J, 1999. Excavations of Chengtoushan site of Lixian county during 1997-1998. Cultural Relic, (6): 4-17. (in Chinese)

He K, Lu H, Zheng Y et al., 2018. Middle-Holocene sea-level fluctuations interrupted the developing Hemudu culture in the lower Yangtze River, China. Quaternary Science Reviews, 188: 90-103.

Heyvaert V M A, Baeteman C, 2008. A middle to late Holocene avulsion history of the Euphrates river: A case study from Tell ed-Der Iraq, lower Mesopotamia. Quaternary Science Reviews, 27(25/26): 2401-2410.

Horton B P, Corbett R, Culver S J et al., 2006. Modern saltmarsh diatom distributions of the Outer Banks, North Carolina, and the development of a transfer function for high resolution reconstructions of sea level. Estuarine Coastal and Shelf Science, 69(3/4): 381-394.

Huang C, Pang J, Zha X et al., 2011. Extraordinary floods related to the climatic event at 4200 a BP on the Qishuihe River, middle reaches of the Yellow River, China. Quaternary Science Reviews, 30(3/4): 460-468.

Hunan Institute of Cultural Relics and Archaeology (HICRA), 2006. Pengtoushan and Bashidang. Beijing: Science Press. (in Chinese)

Hunan Institute of Cultural Relics and Archaeology (HICRA), 2007. Chengtoushan in Lixian County. Beijing: Cultural Relics Press. (in Chinese)

Jin B, 1992. Comprehensive Study of Jianghan Lake Group. Wuhan: Hubei Science and Technology Press. (in Chinese)

Kidder T R, Adelsberger K A, Arco L J et al., 2008. Basin-scale reconstruction of the geological context of human settlement: An example from the lower Mississippi Valley, USA. Quaternary Science Reviews, 27(11/12): $1255-1270$.

Lai H, Mo D, Su C, 2004. Discussion on the evolutionary trend of Lake Dongting. Geographical Research, 23(1): 78-86. (in Chinese)

Li B, Zhu C, Wu L et al., 2013. Relationship between environmental change and human activities in the period of the Shijiahe culture, Tanjialing site, Jianghan Plain, China. Quaternary International, 308/309: 45-52.

Li F, Zhu C, Wu L et al., 2014. Environmental humidity changes inferred from multi-indicators in the Jianghan Plain, Central China during the last 12,700 years. Quaternary International, 349: 68-78.

Li J, 2009. Environmental evolution and human activities during the Holocene in the middle and upper reaches of the Yangtze River: A case study of Dongting Lake Plain and Chengdu Plain. Beijing: Peking University. (in Chinese)

Li L, Wu L, Zhu C et al., 2011. Relationship between archaeological sites distribution and environment from 1.15 Ma BP to 278 BC in Hubei Province. Journal of Geographical Sciences, 21(5): 909-925.

Liu T, Chen Z, Sun Q et al., 2012. Migration of Neolithic settlements in the Dongting Lake area of the middle 
Yangtze River Basin, China: Lake-level and monsoon climate responses. Holocene, 22(6): 649-657.

Meng H, Liu H, Xiang Q et al., 2017. Exploration and excavation of Shijiahe site in Tianmen, Hubei Province from 2014 to 2016. Archaeology, (7): 33-47, 2. (in Chinese)

Meng H, 1997. Prehistoric Cultural Structures in the Middle Reaches of the Yangtze River. Wuhan: Changjiang Literature and Art Publishing House. (in Chinese)

Pei A, 2004. Paleolithic and Neolithic remains on the Liyang Plain in northwestern Hunan and some related problems. Cultural Relic, (4): 24-34. (in Chinese)

Shi C, Mo D, Li C et al., 2011. The relationship between environmental evolution and human activities in Liangzhu Sites Group, Zhejiang Province. Earth Science Frontiers, 18(3): 347-356. (in Chinese)

Shi C, Mo D, Liu H et al., 2010. Late Neolithic cultural evolution and environmental changes in northern Jianghan Plain east of Hanjiang River. Quaternary Research, 30(2): 335-343. (in Chinese)

Shi Z, 1997. Fossil diatoms in borehole No.47 of Jianghan Plain and their significance in paleoenvironmental analysis. Acta Botanica Sinica, 39(1): 68-76. (in Chinese)

Shijiahe Archaeology Team (SAT), 1992. An investigation report on Shijiahe sites. Southern Ethnology and Archaeology, (5): 213-294. (in Chinese)

Stanley D J, Chen Z, 1996. Neolithic settlement distributions as a function of sea level-controlled topography in the Yangtze Delta, China. Geology, 24(12): 1083-1086.

Wang H, 1998. The distribution of Neolithic sites, the transfer of cultural centers and environmental changes in the middle reaches of the Yangtze River. Jianghan Archaeology, (1): 53-61, 76. (in Chinese)

Wang H, 2003. The origin and function of moat settlement in the middle reaches of Yangtze River from the view of moat settlement in Menbanwan. Archaeology, (9): 61-75. (in Chinese)

Wang H, 2007. Qujialing: Prehistoric Culture in the Middle Reaches of the Yangtze River. Beijing: Cultural Relics Press. (in Chinese)

Wang H, Wang X, Li E et al., 2009. The characterisitcs of the main climate change of Jianghan Plain. World Sci-Tech R\&D, 31(6): 1130-1133. (in Chinese)

Wang J, Liu J, 1996. The evolution of sedimentary environment in Taihu Lake during the last 16000 years. Acta Palaeotnologica Sinica, 35(2): 213-223. (in Chinese)

Wang Q, 1999. Influence of the middle and late Holocene relative sea level change on the coastal geomorphic evolution along the north eastern Shandong Peninsula. Geographical Research, 18(2): 122-129. (in Chinese)

Wang Q, Li C, 2009. Sedimentary environment evolution of the Jianghan Plain and its significance to the formation of Three Gorges. Quaternary Sciences, 29(2): 352-360. (in Chinese)

$\mathrm{Wu}$ L, 2013. Environmental archaeology of the mid-Holocene paleofloods in the Jianghan Plain, central China. Nanjing: Nanjing University. (in Chinese)

Wu L, Zhu C, Li F et al., 2015. Prehistoric flood events recorded at the Zhongqiao Neolithic Site in the Jianghan Plain, Central China. Acta Geographica Sinica, 70(7): 1149-1164. (in Chinese)

$\mathrm{Wu} \mathrm{L}, \mathrm{Zhu} \mathrm{C}$, Zheng $\mathrm{C}$ et al., 2014. Holocene environmental change and its impacts on human settlement in the Shanghai area, East China. Catena, 114: 78-89.

Xia Z, Deng H, Wu H, 2000. Geomorphologic background of the prehistoric cultural evolution in the Xar Moron River Basin, Inner Mongolia. Acta Geographica Sinica, 55(3): 329-336. (in Chinese)

Xie Y, Li C, Wang Q et al., 2007. Sedimentary records of paleoflood events during the last 3000 years in Jianghan Plain. Scientia Geographica Sinica, 27(1): 81-84. (in Chinese)

Xie Z, Yuan L, 2012. Fluctuation characteristics of Holocene sea-level change and its environmental implications. Quaternary Sciences, 32(6): 1065-1077. (in Chinese)

Xu R, Xie S, 1994. Environment evolution and the rise and fall of lakes in the Holocene in Jianghan Plain. Regional Research and Development, (4): 52-56. (in Chinese)

Yang D, 1986. On the evolution of the Dongting Lake during the Holocene and the way of management. Geographical Research, 5(3): 39-46. (in Chinese)

Yang H, Xie Z, 1984. Climate and sea-level change along the east coast of China over the last 20,000 years. Oceanologia Et Limnologia Sinica, 15(1): 1-13. (in Chinese) 
Yasuda Y, Fujiki T, Nasu H et al., 2004. Environmental archaeology at the Chengtoushan site, Hunan Province, China, and implications for the environmental change and the rise and fall of the Yangtze River civilization. Quaternary International, 123: 149-158.

Zhang Q, Liu C, Zhu C et al., 2004. Environmental change and its impacts on human settlement in the Yangtze River Delta in Neolithic age. Chinese Geographical Science, 14(3): 239-244.

Zhang X, Cai S, Sun S, 1994. Evolution of Dongting Lake since Holocene. Journal of Lake Sciences, 6(1): 13-21. (in Chinese)

Zhang Y, Li C, Chen G et al., 2005. Characteristics and paleoclimatic significance of magnetic susceptibility and stable organic carbon isotopes from a bore in Zhoulao Town, Jianghan Plain. Journal of China University of Geosciences (Earth Science), 30(1): 114-120. (in Chinese)

Zhao X, Geng X, Zhang J, 1979. Sea-level change of the eastern China during the last 20,000 years. Acta Oceanologia Sinica, 1(2): 269-281. (in Chinese)

Zheng H, Zhou Y, Yang Q et al., 2018. Spatial and temporal distribution of Neolithic sites in coastal China: Sea level changes, geomorphic evolution and human adaption. Science China Earth Sciences, 61: 123-133. (in Chinese)

Zheng Y, Sun G, Chen X, 2012. Response of rice cultivation to fluctuating sea level during the mid-Holocene. Science Bulletin, 57(4): 370-378.

Zhou F, 1990. Changes of Jingjiang Dykes and River-lake System. Nanjing: Hehai University Press. (in Chinese)

Zhu C, Yu S, Lu C, 1997. The study of Holocene environmental archaeology and extreme flood disaster in the Three Gorges of the Yangtze River and the Jianghan Plain. Acta Geographica Sinica, 53(3): 268-278. (in Chinese)

Zhu C, Zhong Y, Zheng C et al., 2007. Relationship of archaeological sites distribution and environment from the Paleolithic Age to the Warring States Time in Hubei Province. Acta Geographica Sinica, 62(3): 227-242. (in Chinese)

Zhu Y, Xue B, Yang X et al., 1997. Characteristics features of the sedimentary samples from the borehole M1 in Jianghan Plain and reconstruction of paleoenvironment. Journal of Geomechanics, 3(4): 79-86. (in Chinese)

Zong Y, Innes J B, Wang Z et al., 2011. Mid-Holocene coastal hydrology and salinity changes in the east Taihu area of the lower Yangtze wetlands, China. Quaternary Research, 76(1): 69-82. 